\title{
Kültürel Jeoloji ve Jeolojik Miras; Yerbilimlerinin Yeni Açılımları
}

\author{
Cultural Geology and Geological Heritage; new initiatives for earthsciences
}

\author{
Nizamettin KAZANCI ${ }^{1,2}$, Nazire ÖZGEN ERDEM ${ }^{3}$, Mehmet KORHAN ERTURAÇ ${ }^{4}$ \\ ${ }^{1}$ Ankara Üniversitesi, Jeoloji Müh. Bölümü, Gölbaşı Yerleşkesi 06830 Gölbaşı, Ankara \\ ${ }^{2}$ Jeolojik Mirası Koruma Derneği, PK 10, 06100 Maltepe/Ankara \\ ${ }^{3}$ Cumhuriyet Üniversitesi, Jeoloji Mühendisliği Bölümü, Kayseri caddesi, 58149 Imaret/, Sivas \\ ${ }^{4}$ Sakarya Üniversitesi, Fen Edebiyat Fak., Coğrafya Bölümü, 54187 Serdivan/Sakarya
}

Öz

Hızlı kentleşme, aşırı nüfus artışı ve işsizlik, özellikle gençlerde doğaya karşı yabancılaşmayı ve yerbilimi eğitimine ilginin azalmasını doğurmuş görünmektedir. Buna karşın büyüyen su ve enerji ihtiyacı, doğal afetler, iklim değişmeleri, sürdürülebilir kalkınma vb. ihtiyaçlar insanları doğaya bağımlı kılmaktadır. $\mathrm{Bu}$ çelişkili durumun ortadan kaldırılması ve kamuoyunda yerbilimlerine ilginin artırılması için eğitim ve uygulamada yeniliklere gereksinim duyulmaktadır. Bu konuda Kültürel Jeoloji ve Jeolojik Miras'1 yerbilimlerinin yeni açılımları olarak takdim ediyoruz. Kültürel Jeoloji, insan neslinin ortaya çıkışından bu yana ortaya koyduğu bütün faaliyetlerine etki eden doğal nedenleri (iklim, coğrafya, çevre, yer şekli, su ve deniz seviyesi değişimleri, yapıtaşları vb), kısaca kültürü yönlendiren jeolojik süreçleri konu edecektir. Yeni bir eğitim ve araştırma dalı olarak ilk kez Türk yerbilimciler tarafından önerilmektedir. Jeolojik Miras, yerkürenin geçirdiği evrimin kalıntıları olup, jeopark ve jeoturizm uygulamaları için mükemmel kaynak değerlerdir. Bunlar günümüzde çok ihtiyaç duyulan doğa koruma ve sürdürülebilir kalkınma için faydalı araçlardır. Hem Kültürel Jeoloji hem Jeolojik Miras için Türkiye büyük potansiyel taşımaktadır.

Anahtar Kelimeler: Kültürel Jeoloji, Yerbilimi açılımları, Jeolojik Miras, Jeosit, Jeolojik koruma

\section{ABSTRACT}

Rapid urbanization, increase in population and unemployment has a great effect on society and as a consequence seems to have caused unawareness to earth sciences. However, increasing demand on water and energy, natural disasters, climate changes and sustainable development still keeps humankind depend on nature. This discrepancy can be avoided by utilizing new initiatives in both education and applications 
to increase public attention to earth sciences. We hereby present Cultural Geology and Geological Heritage as new initiatives of earth sciences. Cultural Geology, aim to explain all natural phenomenon (such as climate, geography, environment, landform, water and sea level changes and raw material sources) which have had effected human activity from the dawn of the species until recent. Briefly study the geological processes that drive the cultural development. It is proposed by Turkish Scientists, for the first time, as a new education and research topic. Geological Heritage, can be defined as artefacts of the evolution of the earth and a perfect example of geopark and geotourism applications, also can be regarded as valuable assets for nature protection and sustainable development. Turkey has a significant potential for both Cultural Geology and Geological Heritage.

Keywords: Cultural geology, new initiatives for earth sciences, geological heritage, geosite, geoconservation

\section{GíRíş}

Aristo'nun M.Ö 4. Asırda Yerkürenin oluşumu hakkındaki söylemlerinden, "Jeoloji" teriminin Diderot tarafindan 'yer kürenin incelenmesi işi’ şeklinde tanımlanmasına (1751) kadar uzun zamanın geçmesi gerekti. Ancak sonrasında, özellikle 1900'lerin başından bu yana, modern jeoloji eğitimi ve araştırmaları ile "yerküre" çok daha açık biçimde anlaşı1ır oldu. Özellikle, Levha Tektoniği kuramı ve radyometrik yaşlandırma teknikleri sayesinde 1960-90 arasında jeolojinin altın çağını yaşadığ1 söylenebilir. Şimdilerde o döneminki gibi sansasyonel ilerlemeler olmuyorsa da okyanus tabanları, yer içi, atmosfer ve iklim değişmeleri, gezegen jeolojisi gibi konularda yoğun çalışmalar olduğunu biliyoruz. Ancak, bu sonuncular çoğunlukla ileri teknoloji ve büyük bütçeler isteyen alanlardır ve maalesef bu araştırma konuları, Türkler dahil çok geniş bir yerbilimci kitlesini "izleyici" konumuna sokmaktadır. Bununla birlikte, bilinir ki, yenilikler ve yeni aç1lımlar hep olacaktır. Önemli olan bunun farkında ve açılım yapma arzusunda olmaktır.
Örneğin, Türkiye ve bulunduğu coğrafya, genel deyişle Orta Doğu, üç kıtanın birleşim yeri olmasının yarattığı harika yerbilimsel olanaklar bulunduruyor. Savaşlara yol açan enerji kaynakları, dört mevsim ve Akdeniz iklimi, Karadeniz, Akdeniz, Kızıldeniz, Umman Denizi gibi iç denizler, kara bağlantılarını kesen ama denizleri bağlayan boğazlar ve kanallar, büyük sıradağlar (Toroslar, Kafkaslar, Zagroslar, Elburzlar, Atlaslar), sıradağların gerisindeki ovalar, düzlükler ve çöller, coğrafik zenginliklerdir. Bunlara ilaveten ilk insan yerleşimi, ilk tarım faaliyetleri, hayvan ve bitkilerin ilk evcilleştirilmesi, ilk şehirleşme, ilk kara ve deniz ticareti, yazının icadı, rakamların bulunuşu gibi uygarlığın temelleri de bu coğrafyada atılmış olup halen çok yoğun araştırma alanlarıdır (Yasuda, 2002). Kültürün oluşması ve gelişmesini kontrol eden bu coğrafya, Kültürel Jeoloji'nin de kavram ve kapsam olarak gelişme yeri olması yadırganmayacaktır. Batıda sıkça kullanılan “Ortadoğu' da kazı çalışmalarına katılmadan gerçek arkeolog olunmaz" özdeyişi isabetli bir vurgulama olduğu kadar, bu coğrafyanın yerbilimcilerine de sorumluluk yüklemektedir. 
$\mathrm{Bu}$ yazı kapsamında yerbilimleri geniş anlamı ile kullanılmakta olup, yerküre ile ilgili eğitim ve araştırma yapan toprak biliminden meteorolojiye, madencilikten coğrafyaya, jeolojiden harita mühendisliğine kadar bütün alanları kapsayacak şekilde alınmaktadır. $\mathrm{Bu}$ alanların gündelik hayata yaygın etkileri ve vazgeçilmezliklerine karşın, orta ve yükseköğretimdeki çekicilikleri ve gördükleri ilgi o nispette değildir. Özellikle maden, jeofizik, jeoloji mühendislikleri giderek daha az tercih edilir olmuşlardır. Azalan ilginin nedenleri ve çözüm yolları bu yazının konusu dışında olmakla beraber, yerbilimlerinde, toplumla daha fazla temas edecek yeni açılımların, yeni eğitim ve araştırma alanlarının ortaya konulması zorunlu görülmektedir. Bu yazıda değineceğimiz Kültürel Jeoloji ve Jeolojik Miras bu amaca hizmet edebilecek yeni disiplinlerdir.

Kültürel Jeoloji, maden jeolojisi, petrol jeolojisi, su jeolojisi (hidrojeoloji), kömür jeolojisi ve çevre jeolojisinde yapıldığı gibi, kültürün oluşmasına tesir eden doğal ve/veya jeolojik olayları inceleyen bilim dalıdır. Tarafımızdan yerbilimleri arasına sokulmaya çalışılmaktadır.

Aşağıda genişçe değinileceği gibi, Kültürel Jeoloji ve Jeolojik Miras, yöntem ve yönelimleri itibariyle birbirlerinden ayrı iki eğitim ve araştırma alanıdır. Birisi kökenleri bu topraklarda olan kültürün doğal olaylarla ilişkisini ele alırken, diğeri insan tarafindan tüketilen doğaya dikkat çeker, doğa koruma fikrini aşılamaya çalışır. $\mathrm{Bu}$ makalede ve dergi özel sayısında bir birinden ayrı iki konunun neden birlikte ele alındığı sorulabilir. Bunlar iki ayrı araştırma alanı olsalar da sebep-sonuç ilişkileri bakımından birbirinden ayrılamazlar; hatta 'zıtların birlikteliği' esasına göre beraber ele alınmaları zorunludur. Kültür ve medeniyet, insanın doğayı işleyerek, yerine göre tahrip ederek ortaya koyduğu ürünler toplamıdır. Son yüzyıl içinde, nüfus artışına göre geometrik artan doğa tahribatı, doğa koruma ve jeolojik miras fikrinin doğmasına sebep olmuştur. İnsanlara doğayı tanımalarını ve daha az tahrip etmeleri çağrısını yapmaktadır. Bu yazıda yeni açılımlar olan Kültürel Jeoloji ve Jeolojik Miras'ın ana ilkeleri tanıtılmaya çalışılmaktadır.

\section{KÜLTÜREL JEOLOJI}

Kültürel Jeoloji'nin ayrıntılı tanımı ve kapsamına girmeden önce belirtilmesi gereken husus, bunun Türk yerbilimcileri tarafından ayrı bir yer bilimi dalı olarak önerilmekte olduğudur. Kapsamı, sinırları, yöntemi ve materyalleri, son yıllarda Türkiye Jeoloji Kurultaylarındaki çeşitli oturumlarda tartışılmakta, kısa notlar ve makalelerle geliştirilmeye çalışılmaktadır (Kazanc1, 2005; Altunel, 2012; http://www.jmo. org.tr/etkinlikler/kurultay/). 2005'den bu yana Ankara Üniversitesi Fen Bilimleri Enstitüsü Jeoloji Mühendisliği Programında, ayrı bir ders olarak okutulmaktadır (www.http://fenbilimleri. ankara.edu.tr/tr/anabilim-dallari/katalog/226/ jeoloji-muhendisligi).

Bilim dallarının gelişmesi ve ders olarak okutulmaları, yasaların oluşması gibidir. Toplumlarda ihtiyaca göre, insan ilişki ve davranışlarını kurallara bağlamak üzere yasalar çıkarılır. Bilimin ön cephesinde olan ülkelerde yeni bir alanda önce araştırmalar yapılır, bunlar yaygınlaşır, giderek araştırma sonuçları uygulamaya girer. Uygulamadaki olumlu sonuçlar zamanla o alandaki bilgilerin daha çok insana ulaşması ihtiyacını getirir ve böylece eğitim başlar. $\mathrm{O}$ alan artık yeni bir bilim dalı olma yolunda ilerler. 
Türkiye'de olağan yaklaşım yurtdışında, özellikle batı ülkelerinde olgunlaşan alanları takip etmektir. Kültürel Jeolojide ise bütün inceleme malzemeleri Anadolu'da ve/veya çevresindeki Kafkasya'da, Ortadoğu'dadır (Şekil 1). Basit bir karşılaştırma yapmak gerekirse, Amerika'daki ilk insan izleri ancak 11-14.000 y1l kadar geriye gidebilirken, Anadolu ve çevresinde 1,8 milyon y1l öncesine ait buluntular söz konusudur (Güleç ve diğ., 1999; Kappelman ve diğ., 2008; Garcia ve diğ., 2010; Callaway, 2016). kalıp kalmadığının araştırılması jeoloji bilgilerine ihtiyaç gösterir. Dolayısıyla, Kültürel Jeoloji'nin ayrı bir dal haline getirilmesi, biraz da Türk yerbilimcilerinin sorumluluğunda görünmektedir.

\section{Kültürel Jeoloji’nin Kapsamı, Bilim Dalları İle İlişkileri}

Bilimsel araştırma ve incelemede, şüphesiz insanların düşüncelerine sınır konulamaz. Bununla birlikte, araştırmalara bir çerçeve çizmeksizin de
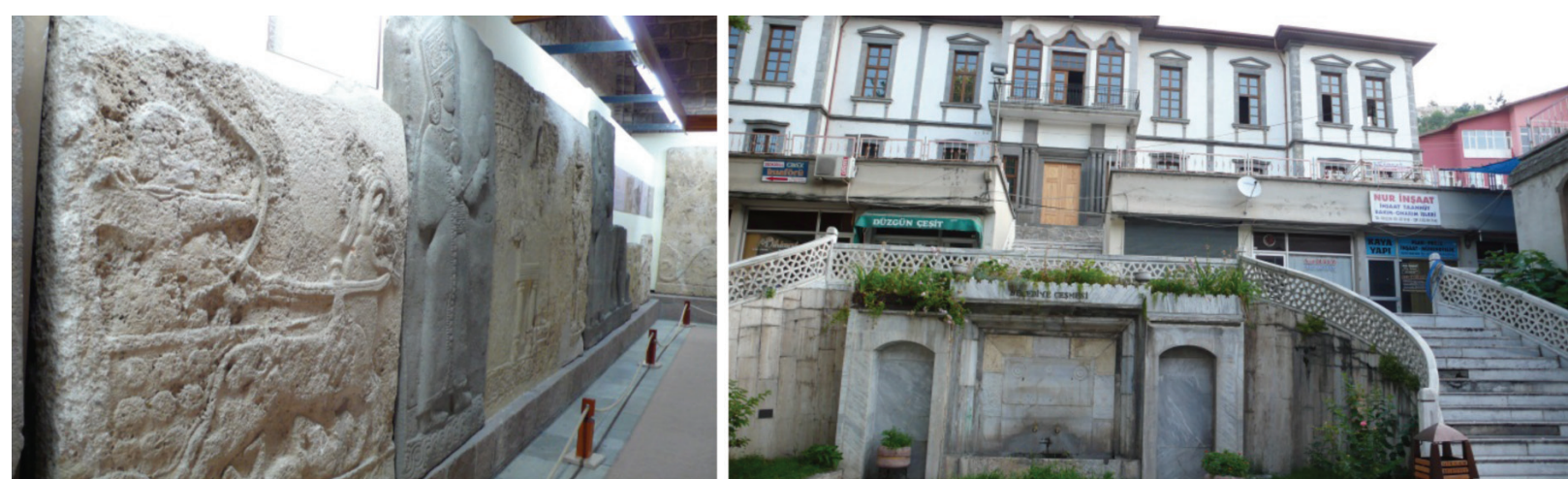

Şekil 1. Anadolu Medeniyetleri Müzesi'nde (Ankara) Asur kabartmaları. Açık renkli olanlar kireçtaşı, koyu renkli olanlar ise bazaltlara oyulmuştur. Aynı zaman dilimine ait kabartmalardaki aşınma farkı litoloji nedeniyledir (a); Niksar Eski Belediye Konağı ve Büyükçeşme. Konağın giriş kapısı iki yanındaki döner sütunlar binanın oturma durumunu gözlemek için konulmuştur (b) (Fotoğraflar; N.Kazancı)

Figure 1. Assyrian reliefs in Museum of Anatolian Civilizations (Ankara). Reliefs are carved into light (limestone) and dark (basalt) colored natural stones. Differentiated erosion is related with the rock lithology (a); Old Municipality Mansion and Great Fountain at Niksar, rotating pillars are installed to monitor the state of statics of the building (b) (Photo: N. Kazancl).

Uygarlığın başlangıcı olan yerleşik düzene geçme, ilk evcilleştirmeler, ilk tarım, ilk çanak çömlek denilince de bu coğrafya akla gelmektedir (Yasuda, 2002; https://en.wikipedia.org/wiki/ Early_human_migrations). Dünyanın ilk insan yapısı Göbekli Tepe veya UNESCO Kültür Mirası olan dünyadaki ilk şehir Çatalhöyük tek başlarına insanlık belgeleridir. Göbekli Tepe'nin dev anıt kaya bloklarının nereden çıkarılıp getirildikleri, Çatalhöyük'ün eski Konya Gölü'nün suları altında planlama ve sonuca gitme mümkün değildir. $\mathrm{Bu}$ nedenle Kültürel Jeoloji’nin kapsamı, kültürün oluşmasına katılan veya gelişmesi sürecinde kullanılan "doğal alt yapı", "doğaya ait her şey" olarak çizilebilir. Somut ve somut olmayan kültür (sırası ile elle tutulur, gözle görülür eserler ile gelenek-görenekler, müzikler, inançlar vb), insan ve insan toplulukları tarafından üretilen ve genellikle olumlu sonuçlar ifade eden kavramlardır. Kültürel jeoloji kapsamında ise ilk insansıdan bu 
yana her türlü iş, ürün ve olgunun doğal yönü ele alınmaktadır. İlk taş aletler, insanların gündelik ve toplumsal yaşamlarını yönlendiren doğa olayları, afetler, doğayı işleme ve kullanmaları, küçük veya büyük eserleri yaparken kullandıkları doğal malzemeler, yer şekilleri, mağaralar, arazi yapıs1, eserlerini yaratırken biraktıkları izler, örneğin maden atıkları, cüruflar, antik taş ocakları kapsam içindedir (Şekil 2). Buna karşın, fosil niteliği olmayan kemik ve vücut kalıntıları, mezar ve mezarlıklar, somut ve somut olmayan kültür eserleri, uygarlık yapılarının estetik, mimarlık özellikleri, yasa, inanç, tarih belgeleri gibi doğa ile ilgisi olmayan unsurlar kapsam dışındadır.

Kültürel Jeoloji’nin kapsamı alanına giren konular ve sorunlar şimdiye kadar yeterince ele alınabilmiş değildir. Bunlara ilişkin ayrı bir disiplin gelişmediği için kısmen konular paleoantropoloji, kısmen arkeoloji, mimarlık ve tarih içinde işlenmiştir.
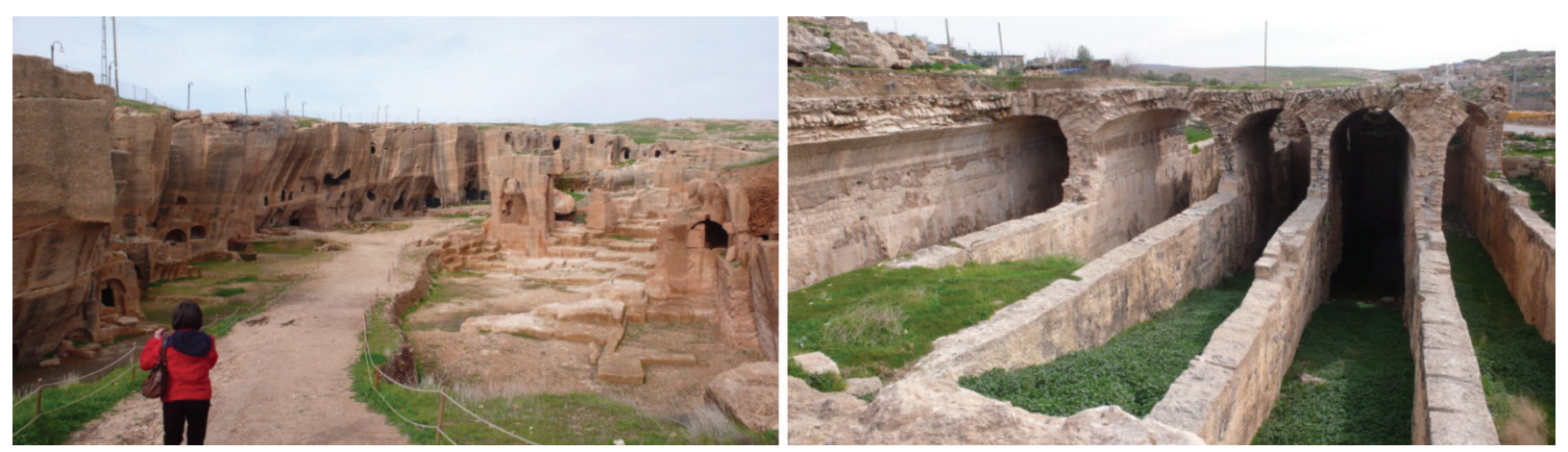

Şekil 2. Dara antik kentinde (Mardin) kaya yerleşimleri ve kentin sarnıçları. Bütün kaya işleri Midyat Formasyonu kireçtaşlarındandır. Kırmızı renk kireçtaşlarının içerdiği demirin oksitlenmesi sonucudur (Foto; N.Kazanc1)

Figure 2. Rock carved settlements and cisterns at the antique city of Dara (Mardin). All structured used limestones of Midyat Formation. The reddish color is due to oxidization of iron within the limestone (Photo: N. Kazancl). 
bilinen bazıörneklerihatırlatmakisteriz. Bunlardan birisi Türk tarihinin en önemli belgelerinden olan Göktürk Yazıtlarıdır. Hakkında pek çok araştırma olan bu kitabeler hakkında on binlerce de internet sayfası bulunmasına karşı1ık, bu yazıların hangi cins kaya üzerine kazıldığına ilişkin tatmin edici bilgi yoktur. En güvenilir kaynak olan Muharrem Ergin'in 192 sayfalık kitabının giriş bölümünde, sadece bir kelime olarak, Kültigin anıtının "siyah kireçtaşı” olduğu belirtilmektedir (Ergin, 2003). Başkaca açıklama olmadığı için bu ifadenin tespit mi tahmin mi olduğu da belli değildir. Böyle yapılarda mermer kullanılması yaygındır. Kaldı ki, onlarca çeşit kireçtaşı vardır. Bu kayalar nereden getirilmiştir? Yaşı, oluşum ortamı nedir? Yazılarda aşınma ve tahribat ne ölçüdedir? Hangi yönlerde daha fazla aşınma olmuştur ve sebepleri nelerdir? Aşınma hızını dikkate alarak anıtlara ömür biçilebilir mi? Asıllarını korumak için aynı kayaların yenisi bulunarak üzerlerine yazıların kopyasını yapılabilir mi? Cevap bekleyen bu sorular, Kültürel Jeoloji kapsamında sorulabilmektedir.

Kültürel Jeoloji uygulamasının güzel bir örneği ise Güney Fransa'da Pirene dağlarındaki Chauvet Mağarası olup, burası mağara duvarlarına kazınmış bazıları renkli çeşitli hayvan figürleri ile ünlüdür (https://en.wikipedia.org/wiki/Chauvet_ Cave). İnsanlığın ilk kaya sanatı (rock art) örnekleri olup 39-32 000 y1llar arasina tarihlenmektedir. UNESCO Dünya Miras Listesi'nin gözde örneklerinden olan resimler, insan beyninin bugünküne benzer çalışmasını gösteren en eski (ilk) işaretlerdir ve bu nedenle mirastır. 1994'de amatör araştırıcılar tarafindan keşfedilen mağara resimlerin güzelliği nedeni ile çokça ziyaret edilmiş ve fakat kısa süre sonra boyaların solduğu, resimlerin silindiği farkedilmiştir. Bunun üzerine mağara ziyarete kapatılmış, yalnızca bilimsel araştırma için uzmanlar girebilmiştir. 2004 sonlarında başlatılan büyük bir Avrupa Birliği projesi kapsamında 55 milyon Avro harcanarak, orijinalinin yakınına, resimlerin olduğu $3000 \mathrm{~m}^{2}$ lik kısmının birebir kopyası yapılmış ve 2015'de bu kopya mağara ziyarete açılmıştır (http:// www.cavernedupontdarc.fr). Orijinal mağarada hangi nedenlerin resimleri bozduğu, resimlerin ilk yapıldığında hangi malzemeler kullanıldığı, ortalama 35000 yıl dayanan boyaların neden çabucak soldukları, resimleri kaç kişinin ne kadar sürede yapmış olabileceği vb gibi konular araştırılıyor ve yayınlanıyor (Zorich, 2016).

\section{Kültürel Jeolojinin Materyal ve Yöntemleri}

Kültürel Jeoloji'nin amacina ulaşmak için kullanacağı materyal ve yöntemleri içselleştirmek için birisi jeolojiye, diğeri canlılar ve kültüre ait iki durumu hatırlamak gerekir. Birincisi, geçmişin bilgilerinin günümüze azalarak geldiğidir. Yerbilimi araştırmaları ile ortaya konulmaya çalışılan jeolojik devirlerin coğrafyası, yeryüzü şartları, denizleri, gölleri, volkanik patlamaları, o dönemlerin canlıları kayaçlara sıkışmış veya gizlenmiş, bütün bu geçmiş özellikleri belirlemek için yerbilimcinin inceleme malzemesi kayaçlar olmuştur. Doğal olarak bu gizlenme sırasında, örneğin fosilleşme süreçlerinde, asıl verilerin çok büyük kısmı kaybolmuştur. Yerbilimci, kayalarda korunan kadarını anlamaya, anlatmaya, yorumlamaya çalışır. Aynı şekilde, jeolojik olaylarda olduğu gibi insan faaliyetlerine kalıntılar da günümüzden geriye doğru hızla azalmaktadır. Örneğin, Orta Pleyistosen'den beri, en az yediyüzbin yıldır yerleşim yeri olan Karain Mağarası'nda (Antalya) yaşama ait kalıntılar 
ancak 11 metre kalınlığında tortullardır. Bu tortul birikiminden o yerleşimi kullanan canlıların kimlikleri, o dönemlere ait iklim özellikleri, iklim değişmeleri, canlıların beslenme alışkanlıkları, çevre ve çevre değişimleri gibi bilgiler üretilmektedir. Aynı şekilde, tarihin en uzun ömürlü devletlerinden Hitit imparatorluğunun başkenti Hattuşa veya en az üç bin yıllık yaşamı olduğu bilinen Truva kalıntıları da birkaç metre kalınlığında taş toprak yı ğınlarıdır. Bu yığıntılardan şaşaalı geçmişleri öğrenilmeye çalışı1ır.

İkinci özellik, küçük veya büyük bütün insan yerleşimlerinin nehir, göl veya bol sulu tatlı su kaynakları yakınında olduğudur. Çünkü insanlar ve beraberlerindeki hayvan sürülerinin yeterli suya ihtiyaçları vardır. Çoğu kez yaşam tarzlarını su durumuna göre değiştirmişledir. Varlığı yakın zamanlarda farkedilen ve dünya mirası olarak tescillenen, Orta Çağ'dan bu yana kuzey Afrika, Ortadoğu ve Orta Asya'da kullanıldığı anlaşılan yeraltı su şebekesi (kanat, kariz) bunun en güzel örneklerindendir (ICOMOS, 2015). Bu gibi tatl su kaynaklarının oluşumu ve zaman içindeki değişimleri klasik jeoloji yöntemleri ile kolayca anlaşılmaktadır. Yerleşik düzen öncesi, insan nesli, yiyecek bulundurmayan dağların zirveleri hariç yeryüzünün her tarafını kullanmıştır, ancak o zamanlara ait kalıntılar hem dağınık, hem de çok sinirlidir.

Özetle, kültürel jeoloji materyalleri ekseriyetle paleoantropoloji, arkeoloji, tarih ve mimarlık materyalleri ile birlikte bulunur. Mağara ve mağara tortulları, höyükler, tümülüsler, eski yerleşim yerleri, antik maden ve taş ocakları, doğal taş esaslı tarihi ve kültürel yapılar, yerleşim ve savaşlarda kullanılan kara parçaları, yer şekilleri, göl, gölcük, bataklıklar, taşkın ovaları, eski topraklar, iklim ve deniz seviyesi değişimini işaret eden organik ve inorganik kayıtlar ilk akla gelenlerdir.

Kültürel Jeoloji'nin materyal ve yöntemlerini bir bütün halinde anlatan örneklerden birisi, taş işçilikleri ile zengin tarihi Mardin şehir merkezidir. Tüm şehir ya kayalara oyulmuş ya da oymalı taşlarla süslenmiştir. Bazı bina cephelerinde üzgün veya sevinçli yüz ifadeleri belli heykellerin varlığı görenleri şaşırtır, hayran bırakır. Taş ustalarının o eserleri yaratmadaki sırrı, aslında Eosen yaşlı kireçtaşı (Midyat formasyonu) olup yer altında iken tebeşir gibi kolayca şekillenebilen, yeryüzüne çıktığında ise suyunu kaybedip aşırı derecede sertleşen jeolojik miras nitelikli, doğal Midyat Taşı'nda yatar (Kazancı ve Gürbüz, 2014). Buna karşın, endüstriyel hammadde özelliği dışında, Midyat Taşı'nın kültürel jeoloji bakımından nitelikleri henüz yeterince ortaya konulmuş değildir.

Bir başka örnek Büyük Moğol İmparatorluğu'nun oluşumuna (1206-1227) iklim etkisinin yeni anlaşılmasıdır. Cengiz Han'ın 21 y1l gibi göreceli kısa bir zaman diliminde, o günün bilinen bütün dünyasının neredeyse tamamına yakınını, Kore'den Ukrayna'ya, Hint Okyanusundan Kuzey Denizi'ne kadar fethedip büyük bir imparatorluk kurmasının sırları sürekli merak ve araştırma konusu olmuştur. Günümüz şartlarında salt gezmek için bile çok geniş olan bu büyük coğrafyanın savaşlarla ele geçirilmesi inanılmaz bir olgudur. Bu konuda tatmin edici bir cevap, yakın zamanda Moğolistan platosundaki bir bataklıkta yapılan dört metrelik sondaj karotlarının incelenmesiyle bulunmuştur (Pederson ve diğ., 2014). Karotlardaki palinoloji verileri 13. Asırda, kısa dönemli kuraklıklar olsa da iklimin ekseri 1lıman ve yağgşlı, buna bağlı olarak otsu bitkilerin çok gür ve yaygın olduğunu göstermiştir. İklime 
ait palinoloji bulguları, bölgedeki eski ağaçlar üzerinde yapılan dendrokronoloji incelemeleriyle desteklenmiş ve güvenilir hale getirilmiştir (Pederson ve dĭ̆. 2014). Yazarlar, o döneme ait Çin yazılı kaynaklarını da kullanarak, dev imparatorluğun kuruluş sırrını "iklim ve hı"” olarak açıklamaktadırlar. Şöyle ki, bütün Asya halklarının geçim kaynağı ve Cengiz Han'ın kullandığı Moğol atları kısa bacaklı ama çok uzun mesafelere koşabilen dayanıklı hayvanlardı. Ilıman ve yağışlı iklim şatlarında büyük sürüler halinde üretiliyorlardı ve sefere çıkan her asker beraberinde 8-10 at taşıyabiliyordu. Çok sayıda at orduya sürat kazandırdığ 1 gibi, yiyecek olarak da kullanılıyor, erzak taşıma sorununu ortadan kaldırıyordu. Geniş otlaklar atlar için yem taşımaya gerek bırakmıyor, ordunun dinlenme zamanı atların beslenmesi demek oluyordu. Özetle, 1lıman ve yağışlı iklimin yarattığ hayvan besleme olanakları ile Moğol atlarının sağladığ hız, Cengiz Han'ın askeri dehasıyla birleşince tarihteki en geniş sınırları olan imparatorluk doğmuştur.

\section{Kültürel Jeoloji İçin Ülke Potansiyeli}

Yukarıdaki satırlarda örnek olarak değinilen konu ve yerlerin yüzlercesi tekrarlanabilir. Çeşitli su yapıları, eski göl düzlükleri, Anadolu'daki medeniyetlerin çokluğu, bunlara ait binlerce kalıntı Türkiye'deki büyük araştırma potansiyelinin işaretleridir. Bunlar üzerinde olanaklar ölçüsünde çalışılıyor. Arkeoloji çalışmalarının zahmetli ve pahalı olması nedeniyle, ülkemizde yurtdışı gruplarının da kazı yapmalarına izin verilmektedir. Yerli yabancı bütün çalışmalarda, şüphesiz yerbilimi ve yerbilimi yöntemleri kullanılmaktadır. Çoğu kez, bu çalışmalar "Jeoarkeoloji” olarak tanımlanmakta ve arkeolojinin açılımı olarak sunulmaktadir (https://en.wikipedia.org/wiki/ Archaeology). Yani, Jeoarkeoloji, arkeolojinin gereksinim duyduğu bazı bilgilerin sağlanması çalışmalarıdır. Aynı yaklaşımla arkeolojide diğer alanlarda da arkeoastronomi, arkeobotanik, arkeozooloji vb çalışmaları (arkeolojide yeni açılımlar?) mevcuttur. Burada tanıtmaya çalıştı̆̆ımız Kültürel Jeoloji ise onlardan farklı, jeolojinin bir açılımıdır. Yerbilimlerinin başta "mermer" ve "menderesli akarsu" olmak üzere birçok kavramına kaynaklık eden Anadolu coğrafyası "Kültürel jeoloji” çalışmaları ile daha çok aydınlanabilecektir.

\section{JEOLOJIK MIRAS}

"Miras" kavramı ve olgusu bütün kültürlerde mevcuttur ve genellikle "aile yakınlarından kalma harcanabilir para, mal mülk" olarak anlaşılır. Jeolojik Miras ise, miras kelimesinden dolayı sanılanın aksine, cansız çevrenin bize sağladığ 1 doğal zenginlik olarak tarif edilemez. O, geçmişteki dünyanın bugünkü dünyaya bıraktığg mirastır. Bir başka ifade ile "yerkürenin geçirdiği jeolojik evrimin belgeleri”dir. Bu yüzden jeolojik miras teriminin ilk kullanıldı $\breve{g}_{1}$ Digne Bildirgesinin ad1 veya başlığı "Yerkürenin Hakları" olmuştur ve ilk maddesi şöyledir; İnsan hayatının bir kere yaşandığının kabul edilmesi gibi yerkürenin hayatının da tek olduğunun anlaşılması zamanı gelmiştir (www. Progeo.ngo/Digne Decleration). $\mathrm{Bu}$ bir kere yaşanan yerkürenin hayatındaki (jeolojik) olayları, aradan milyonlarca yıl geçtikten sonra anlamamiza yarayan izlere (ki, yerine göre istif, kayaç, mineral veya fosil topluluğu, yerşekli, yap1, doku, arazi parçası vb olabilir) jeolojik sit (jeosit), bunlardan yok olma tehdidi 
altında olanlara, koruma ihtiyacını vurgulamak üzere "jeolojik miras” diyoruz (ProGEO group, 1995; Kazanc1, 2010) (Şekil 3, 4) Çoğu kez bu iki terim birbirlerinin yerine kullanılsa da jeosit daha çok bilimsel, jeolojik miras (jeomiras) popüler anlamlardadır. Örneğin, UNESCO ve IUCN (International Union for Nature Conservation) mevzuatında doğa koruma bağlamında "jeolojik miras" terimi tercih edilir (www.IUCN.org/ theme/protected_areas). Bu yazıda jeolojik miras konusunun kuramsal veya felsefi açıdan çok, uygulama kısmına değinilecektir.

\section{Kapsamı ve Diğer Alanlar İle İlişkileri}

Jeolojik miras veya jeosit kavramlarının kapsamları ve başka dallar ile ilişkilerini anlamak için ortaya çıkış süreçlerine göz atmak gerekir. İkinci Dünya Savaşı'nın Avrupa'da yarattığı büyük fiziki tahribatı onarmak için, başta Almanya ve Fransa olmak üzere bütün ülkeler yoğun bir üretim-tüketim faaliyetine giriştiler (Türkiye'den Avrupa'ya işçi gönderilmesi de bu sırada başladı). Artan faaliyetler daha çok hammadde gerektirip, daha çok maden, daha çok endüstriyel hammadde tüketilirken, bunların başta kirlilik olmak üzere büyük çevre tahribatı yarattı̆ğ görülmeye başland1. Paralel olarak, artan refah düzeyi ile birlikte çevre bilinci gelişti ve doğa koruma ihtiyacı ortaya çıktı. Özellikle yerbilimciler, temel bilgi kaynaklarının hızla yok olduğunu hayretle fark ettiler ve Digne Bildirgesi bir feryat ifadesi, bir çı̆̆lık olarak yayınlandı (1991), kısa süre sonra da gereği için ProGEO kuruldu (1993) (www. progeo.ngo/history.html). Yine bu dönemde fark edildi ki, jeolojik mirasın korunması için bireysel veya ülkesel düzeyde değil, bütün yerbilimcilerin ortak hareket etmeleri gerekmektedir. Örneğin Devoniyen'e adını veren Devon kasabasındaki istif yalnızca İngilizler için değil bütün yerbilimciler için bilimsel "kaynak değer" durumundadır. $\mathrm{Bu}$ yaklaşımla küresel kabul görecek jeosit ve jeolojik miras belirleme kriterleri oluşturulmaya başlanmıştır (Wimbledon ve diğ, 1995; ProGeo Group, 1998). Memnuniyetle belirtilmesi gereken husus bu konuda ülkemiz dahil Avrupa'da ve dünyanın öteki ülkelerindeki bilimsel ve sosyal gelişmeler beklenilenden hızlı olmuştur (Burek ve Prosser, 2008; Wimbledon ve Smith-Meyers, 2012).

Jeolojik Miras, yerbiliminin yapılabilmesi için gereklidir. Jeolojik mirasın korunması (= Jeolojik koruma) genel doğa koruma faaliyetlerinin bir parçası olmanın ötesinde, yerbilimleri için yaşamsal öneme sahiptir, çünkü bilginin damarlarının korunması veya kurutulması söz konusudur. Bununla birlikte IUCN mevzuatında jeolojik miras "biyoçeşitlilik" içinde değerlendirilmektedir ve canlı varlıklar kadar ihtimam gördüğ̈ söylenemez. Yine de UNESCO Dünya Miras Listesi'nin Doğal Alanlar kategorisinde çok sayıda jeolojik oluşumların varlığ1 görülmektedir (http://whc.unesco.org/en/ list). 


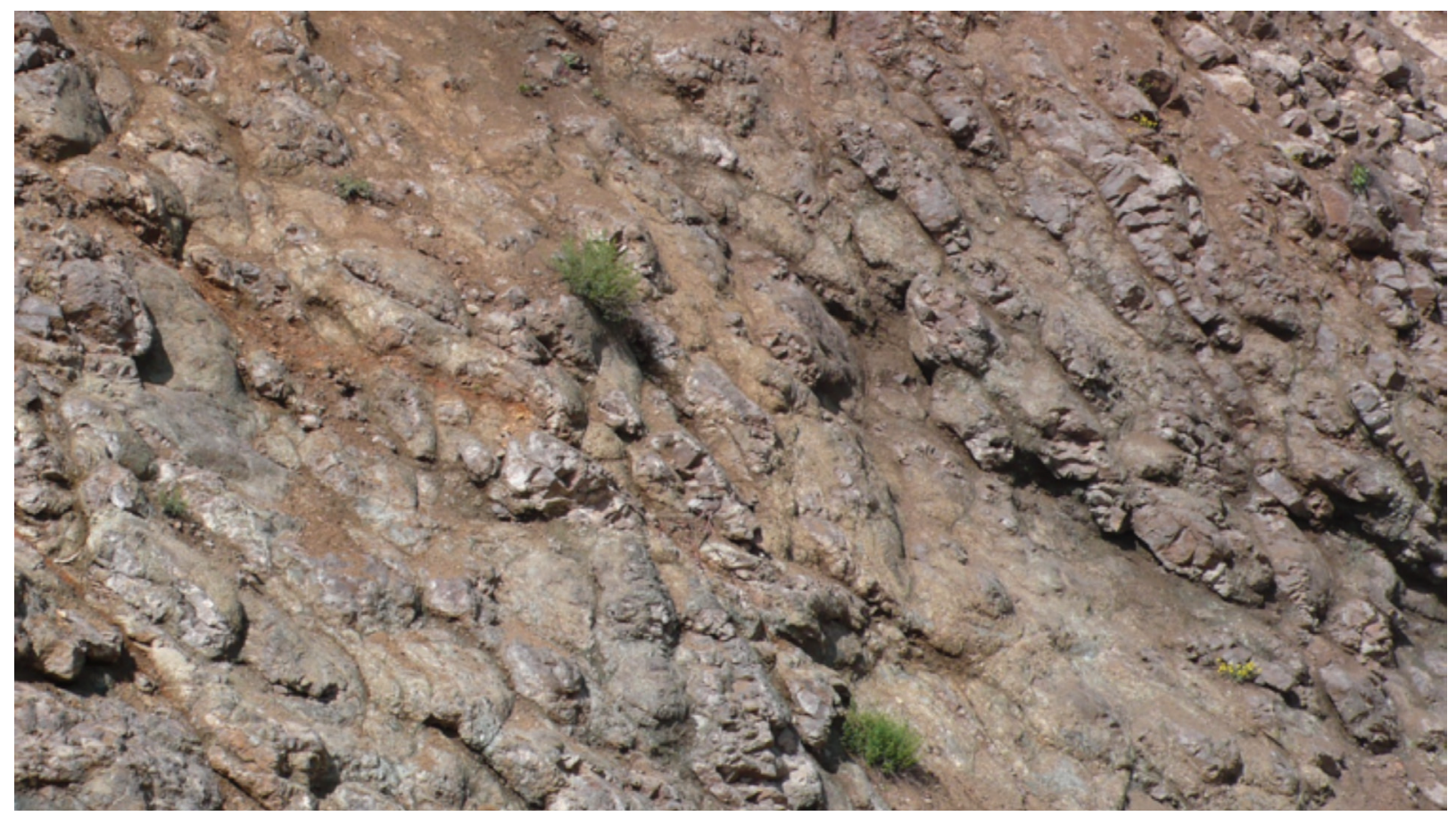

Şekil 3. Kretase yastık lavları, Küre, Kastamonu. Jeositlerin her zaman etkileyici görsellikleri olması gerekmiyor. Buradaki gibi temsil ettiği olayı açıklayacak şekilde olması yeterlidir (Foto: N.Kazancı)

Figure 3. Pillow lava formations of Cretaceous at Küre, Kastamonu. Geosites does not require to be visually attractive all the time, the information they preserve on the process is adequate (Photo: N. Kazancl)

Jeolojik Miras, ülkelerin bilimsel zenginlikleri demek olduğundan uluslararası kurallara göre envanterlerinin yapılması ve bunların dünyaya tanıtılması önerilmektedir (Wimbledon ve Smith-Meyers, 2012). Bilimsel tanıtım önceliklidir, çünkü böylece jeositlerin bölgesel veya küresel olarak birlikte değerlendirilmeleri ve giderek uluslararası bilimsel işbirliği içinde dünyanın jeolojik evrimini anlamaya katkı sağlayabileceklerdir.

Herhangi bir bölge veya ülkede çok sayıda jeosit bulunması mümkündür. Bunların başka bölge veya ülkelerle ortak değerlendirilebilmeleri için "jeosit çatı listeleri”nin oluşturulması ikinci adımdır. Çatı liste her bölge veya ülke için bir tanedir, çünkü orada doğal belgeleri (jeosit) bulunan bütün jeolojik geçmiş ve geçmişteki olaylar başl1klar halinde verilmiştir (Progeo group, 1998). Türkiye için Güneydoğu Avrupa ülkeleri ile uyumlu bir çatı liste yakın zamanda oluşturulmuş ve yayınlanmıştır (Kazancı ve diğ., 2015).

Tarihsel gelişime bakıldığında, Jeolojik Koruma'nın, Doğa Koruma ve Jeolojik Miras kavramlarından çok önce ortaya çıktığı görülür. $\mathrm{Bu}$ terimler kullanılmaksızın, bilinen en eski koruma teşebbüsü Almanya'daki Baumann mağarasına olmuş (1665), ancak belirgin ilerleme sağlanamamıştır (Doughty, 2008). İlk başarılı koruma ise Birleşik Krallık'ta Giant Causeway isimli bazalt sütunlarının taş ocağ 1 olarak işletilmesinin belediye meclisi kararıyla durdurulmasidir (1741) (Erikstad, 2008). Günümüzde jeosit tespiti ve jeolojik koruma gelişmiş ülkelerde yaygındır. Örneğin Tuna 
Nehri'nin doğduğu yer, hem İspanya'da hem Romanya'da dinozor yumurtalarının olduğu yerler, Waterloo Savaşı'nın geçtiği yerler de jeolojik mirastır. Buradan, jeolojik mirasın çevre bilincinin doğmasina, hatta vatan sevgisinin bilimsel temellere oturtulmasina katkıda bulunduğu söylenebilir. $\mathrm{Bu}$ haliyle jeolojik mirasın eğitim, tarih, coğrafya, ekoloji, peyzaj, yurttaşlık, çevre koruma alanları ile yakın ilişki içinde olduğu açıktır. Yakın zamanda Sivrihisar (Eskişehir) kayalıklarına taş ocağı işletme ruhsatı verilmesi duyumlarına karşı, bu kayalıkları korumak için vatandaşların UNESCO Somut Olmayan Kültürel Miras Listesi'ne kaydedilmesi girişimleri, benzer duyarlığın ülkemizde de varlığının işaretleri sayılmalıdır (http://www. milliyet.com.tr/sivrihisar-kayalarinin-kulturelmiras-eskisehir-yerelhaber-1746820/).

Çizelge 1. 2015 yılı itibariyle Türkiye'de çeşitli kategorilerde tescilli doğa koruma alanları (çeşitli kaynaklar taranarak tarafımızdan hazırlanmıştır)

Table 1. Types of natural protection in different categories by law in Turkey (complied by using various resources)

\begin{tabular}{|c|c|c|c|}
\hline Koruma Türü & Sayısı & Yasal Dayanak & İlgili Kurum ve Kuruluş \\
\hline Dünya miras alanı & 15 & UNESCO 1972 sözleşmesi & Kültür ve Turizm Bakanlığ 1 \\
\hline Arkeolojik sit'ler & 14840 & $\begin{array}{l}2863 \text { sayılı Kültür ve Tabiat Varlıklarını } \\
\text { Koruma Yasası }\end{array}$ & Kültür ve Turizm Bakanlığ \\
\hline Taşınmaz kültür varlıkları & 100729 & $\begin{array}{l}2863 \text { sayılı Kültür ve Tabiat Varlıklarını } \\
\text { Koruma Yasası }\end{array}$ & Kültür ve Turizm Bakanlığ \\
\hline Milli Park & 42 & 2873 sayıl1 Milli Parklar Yasas1 & Orman ve Su İşleri Bakanlığı \\
\hline Tabiat Park1 & 31 & 2873 sayıl1 Milli Parklar Yasas1 & Orman ve Su İşleri Bakanlığı \\
\hline Doğa Koruma Alanı & 107 & 2873 sayıl1 Milli Parklar Yasası & Orman ve Su İşleri Bakanlığ1 \\
\hline Tabiat Anitı & 184 & 2873 sayılı Milli Parklar Yasas1 & Orman ve Su İşleri Bakanlığg \\
\hline $\begin{array}{l}\text { Yaban Hayatı Koruma } \\
\text { Sahası }\end{array}$ & 81 & Kara Avc1lığ 1 Yasası & Orman ve Su İşleri Bakanlığı \\
\hline Koruma Ormanı & 58 & Orman Kanunu & Orman ve Su İşleri Bakanlığı \\
\hline Gen Koruma Sahası & 239 & Orman Kanunu & Orman ve Su İşleri Bakanlığ1 \\
\hline Biyolojik Koruma Alanı & 7 & Orman Kanunu & Orman ve Su İşleri Bakanlığ1 \\
\hline Özel Koruma Bölgesi & 16 & Çevre kanunu & Orman ve Su İşleri Bakanlığ1 \\
\hline Tohum Koruma sahası & 373 & Orman Kanunu & Orman ve Su İşleri Bakanlığ1 \\
\hline Doğal Sit'ler** & 1273 & $\begin{array}{l}2863 \text { sayılı Kültür ve Tabiat Varlıklarını } \\
\text { Koruma Yasası }\end{array}$ & Orman ve Su İşleri Bakanlığg \\
\hline Sulak Alan & 135 & Ramsar Sözleşmesi & Orman ve Su İşleri Bakanlığı \\
\hline Ramsar Alanı & 14 & Ramsar Sözleşmesi & Orman ve Su İşleri Bakanlığı \\
\hline Biyosfer Rezervi & 1 & $\begin{array}{l}\text { Milli Parklar Yasası } \\
\text { Orman kanunu }\end{array}$ & Orman ve Su İşleri Bakanlığg \\
\hline UNESCO Jeopark1 & 1 & - & $\begin{array}{l}\text { Kula ve Manisa Büyükşehir } \\
\text { Belediyesi }\end{array}$ \\
\hline Jeosit & 815 & - & $\begin{array}{l}\text { JEMİRKO- Jeolojik Miras1 } \\
\text { koruma Derneği }\end{array}$ \\
\hline
\end{tabular}

* Bazıları hem Ramsar alanı hem Milli Park olarak tescillidir.

*** Bunların 150 kadarı Jeosit olarak da kayıtlıdır. 


\section{Jeolojik Koruma Yöntemleri}

Türkiye'de jeolojik koruma, doğa koruma mevzuatı içindedir. Yasa ve yönetmeliklerde kendi terimleri ile değil (jeosit, jeomiras, jeopark vb) "tabiat varlıkları" olarak yer alır ve çok fazla rağbet gördüğü söylenemez. Bunun en belirgin işareti yetkili kurumlarda görev alan yerbilimci sayısının azlığıdır. Oysa rahatlıkla söylenebilir ki, ülkemizde jeolojik miras fikri, çevre ve çevre koruma fikrinden çok önce başlamış ve korumaya dikkat çeken çeşitli yayınlar yapılmıştır (Ketin,1970; Arpat, 1976; Arpat ve Güner, 1976; Öngür, 1976; Özdemir ve diğ., 1986; Kazancı ve diğ., 2005). Bununla birlikte biyoçeşitlilik ve doğa koruma konusunda ilgili kurum ve kuruluşların hassasiyetinin gittikçe arttığ1 görülmektedir (Küçük ve Ertürk, 2013) (Çizelge 1).

Jeolojik korumanın eğitimle başladığ 1 genel kanaattir (Burek ve Prosser, 2008; Kazanc1 ve diğ., 2012). İkinci sirada gelen husus, jeolojik mirasa kamuoyunun sahip çıkmasının sağlanmasıdır. Çünkü çoğunlukla kırsal alanlarda bulunan jeolojik mirası korumak için her birine ayrı güvenlik sağlamak mümkün değildir. Yakın zamandauluslararası kamuoyunda veIUGS, IUCN, UNESCO, ProGEO gibi kuruluşlarda gelişen fikir, jeolojik mirası yöre halkının kalkınması için tanitım ve turizm araci yapmaktır (Dowling ve Newsome, 2005). Aynı yaklaşımla UNESCO'da jeopark programı hem doğa korumanın hem de sürekli kalkınmanın aracı olarak gittikçe prestijli hale gelmektedir (http://www.unesco.org/naturalsciences/environment/earth-sciences/unescoglobal-geoparks/). BirleşmişMilletlerTeşkilatı'nın yayınladığı 2030 Uluslararası Sürdürülebilir Kalkınma Hedeflerinin önemli bölümü doğa koruma ile alakalıdır. Özetle, jeolojik korumanın etkili yöntemi her ülkenin kendi vatandaşlarına jeolojik mirasını tanıtması, kalkınma aracı olarak hazırlamasıdır. Bu kapsamda Jeoturizm ve Jeopark uygulamaları öne çıkmaktadır.

\section{Jeolojik Miras Potansiyeli}

Ülkelerin jeolojik çeşitliliği (geodiversity) ve jeolojik miras varlığı, şüphesiz doğrudan coğrafik konumları ile ilgilidir ve bu bakımdan Türkiye eşsizdir. Ancak bu eşsiz oluşu söyleyen veya iddia eden yerbilimcilerdir. Bu coğrafik eşsizliğin veya jeolojik potansiyelin işe yarayabilmesi için kamuoyunun onlardan haberdar olması, jeolojik zenginliğin vatandaş lehine kullanılması gerekir. Burada da yerbilimcilere görev düştüğü anlaşılıyor; jeolojik zenginliğin halka, özellikle de genel ve yerel yöneticilere tanıtılması öne alınması gereken uğraştır. Bu farkındalığın sağlanması ile jeoturizm potansiyeli artacağı gibi, jeolojik korumaya da hizmet edilecektir.

Bir ülkedeki jeolojik miras potansiyeli tescilli alanlar ile orantılıdır. Tescil mevzuat ülkelere göre değişmektedir (Wimbledon ve Smith-Meyers, 2012). Ülkemizde tüm doğa koruma işleri uluslararası sözleşmeler, 2863 sayılı Kültür ve Tabiat Varlıklarını Koruma Kanunu, 2873 sayılı Milli Parklar Kanunu, Orman Kanunu ve Çevre Kanunu çerçevesinde yürütülmektedir (Çizelge 1). Jeolojik varlıkların tescili konusunda Doğa Koruma ve Milli Parklar Genel Müdürlüğü, yönetiminde ise Tabiat Varlıklarını Koruma Genel Müdürlüğü yetkilidir. Türkiye'nin korunan veya korunması arzu edilen değerler olarak kültür varlıkları öne çıkmaktadır. Buna karşın doğal koruma alanları ülke büyüklüğü ve jeolojik zenginliği ile orantılı değildir (Çizelge 1). Bunun çok çeşitli sebepleri olduğu doğrudur, ancak korunan alanların başarısız yönetimi korunan 
alanlar aleyhine işlemektedir. Yakın zamanda milli parklardan birinin alanı daraltılınca, yerel yöneticinin bundan duyduğu memnuniyet ve tüm milli parkın iptalini istemesi, üzerinde durulması gereken bir konudur (http:/www.hurriyet.com.tr/ baskomutanlik-milli-parki-kuculuyor-40319423, 27 Aralık 2016).

\section{DEĞERLENDİRME VE SONUÇ}

Genel olarak bütün dünyada gözlenmekle birlikte, Türkiye'de büyük şehirlere göç çok hızlı yaşanmakta olup, kırsal alanlar neredeyse boşalmaktadır (TUIKK, 2015). Bu durumun getirdiği sonuçlardan birisi doğaya habersiz yaşama, dolayısıyla doğa tahribatının farkına varamamaktır. Bunun eğitimdeki sonucu ise doğa ve yerbilimlerine ilginin azalması, örneğin jeoloji, jeofizik, maden mühendisliği bölümlerinde büyük kontenjan açıkları olmasıdır. Buna karşılık doğal afetler, yerleşim yeri seçimleri, kuraklık, iklim değişmeleri, deniz seviyesi oynamaları, artan su ve enerji ihtiyacı gibi pek çok yaşamsal yerbilimi konuları toplumları daha fazla tehdit etmektedir. Doğaya yabancılaşma-yerbilimlerinden uzaklaşma-doğal afet ve doğal kaynak ihtiyacının artması gibi çelişkili durum söz konusudur. Bütün bunlara karşın çözüm yine eğitimde ve bizzat yerbilimlerinin içinde aranmalıdır. Yerbilimleri değişen toplum yapısına uygun yeni açılımlarla bu sorunların üstesinden gelebilecektir.

\section{EXTENDED ABSTRACT}

Rapid urbanization causes alienation to nature, unemployment and as a consequence leads to unawareness to earth sciences. During the last decade, at least 40 departments of geology in USA and EU have either been closed or changed their formats. At Turkey's side, recently many earth

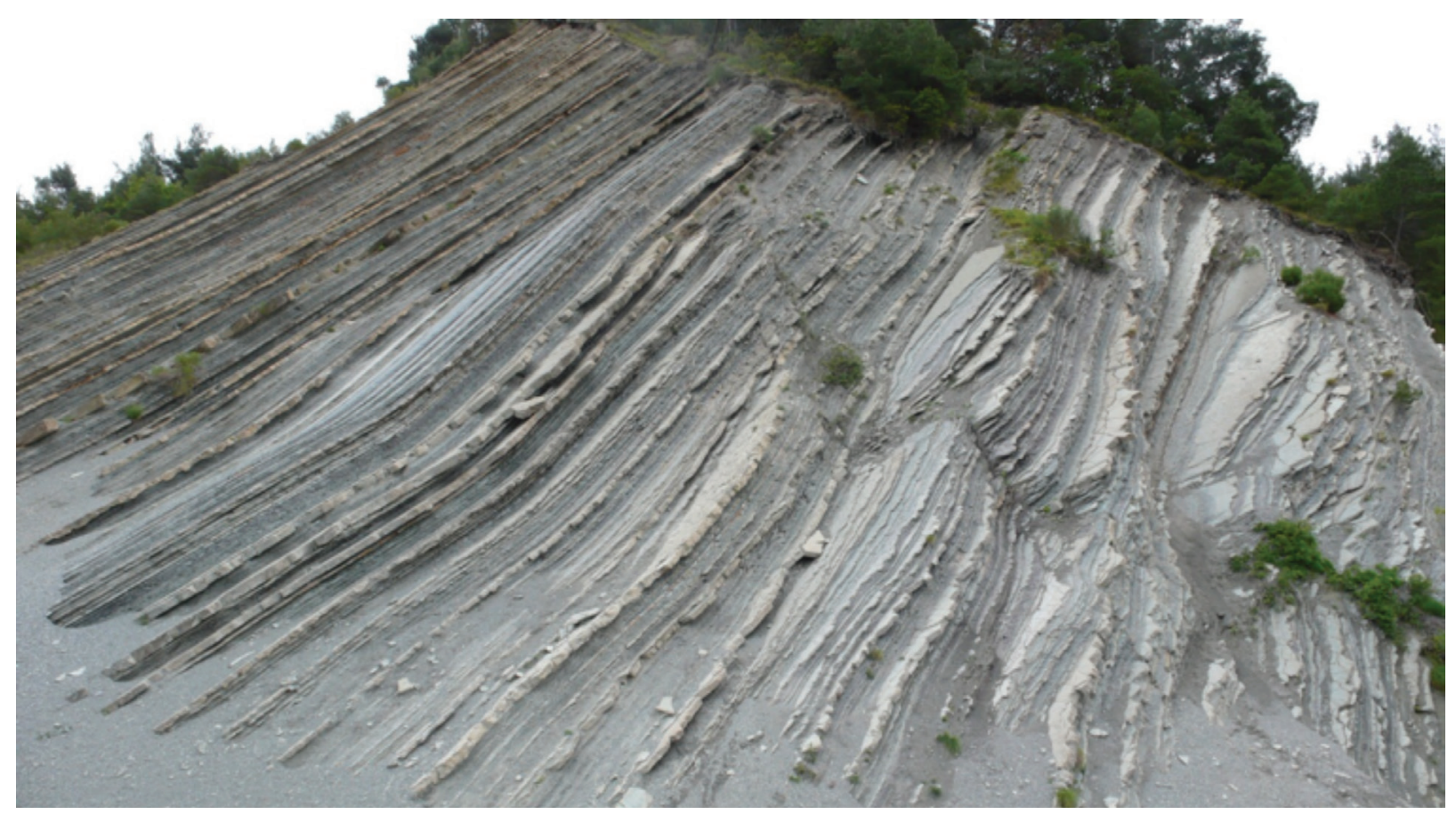

Şekil 4. Üst Kretase filişinin kumlu ve marnlı fasiyesleri, Alaçam, Samsun (Foto. N.Kazanc1)

Figure 4. Sand and marl facies of Late Cretaceous flysch, Alaçam, Samsun (Photo: N. Kazancı) 
science departments (geology, geophysics and mining engineering) has not been able to fulfill their student quota except those which are located in major cities such as in Ankara and Istanbul. Yet, every society has increasing need for natural resources sciences, thus earth sciences, in order to mitigate natural hazards, planning settlements, climate change, need for energy, water resource management. This discrepancy may be explained that earth scientists require new initiatives and ways to communicate with society. With the help of these new approaches and initiatives, relationships between the daily life and natural sciences can be realized and explained. Within this context, we propose the disciplines CULTURAL GEOLOGY and GEOLOGICAL HERITAGE for explaining the related research, education and application, which are the subject of this manuscript.

Cultural Geology, aims to reveal and understand the natural processes and/or causes which has had direct or indirect impact on evolution of culture and civilization. Civilization, by definition, is a result of the struggle between the mankind and nature since the first man to early $20^{\text {th }}$ century. Adaptation to climate and geography, chasing and adapting nutrition sources, processing and consuming natural resources, utilization of surface and underground water sources are primary occupation of humankind from the first settlements to modern era.

Briefly, culture and the whole human activity is driven by natural phenomenon. Physical or not, recently or at the past, the formation of cultural heritage has been controlled by natural processes such as climate, landforms, morphology, wet lands, coasts, sea level changes. These processes are expected to be studied by using methodologies of earth sciences and thus are the research topics of cultural geology. On the other hand, earth science (i.e. geology, geography, geophysics) topics, either recent or past, which does not concern human life is not at the scope of cultural geology. Also, it does not study historical monuments or archaeological archives which are the topic of archeology. Archeogeology which can be considered as a sub-discipline of archeology, provides detailed, complementary information on a site by using earth science methodologies, is a focused application of cultural geology without fully corresponding to the definition we aim to describe here.

Cultural Geology, studies the natural processes that drive the human life and humannature interaction starting from late Plioceneespecially late Pleistocene- to recent, by using archives such as caves, stone tools, terraces, historical settlements, historical stone and mine facilities, wet lands and river beds. Middle East and especially Anatolia, which faced first human migrations and hosted early settlements, form ideal study areas during the development of Cultural Geology as a new discipline.

The concept "environmental protection" has been born with extreme pollution caused by increase in population and industry. Simultaneously, intense consumption of raw material, open mining and rock quarry facilities, expanding settlements, artificial water reservoirs, which are often disregarded and ignored, caused destruction in natural landscapes which are archives of earth sciences. The naked truth is, either rock, section, mineral or fossil assemblage, landscape and landforms, these mute archives are not renewable and once destroyed they are not replaceable. 
The Digne Decleration (1991) stands for the first out loud objection of the earth scientists to this situation. Afterwards the terms "geological protection" and "geological heritage" are founded. Geological heritage is a more popular expression of Geological site (geosit) which is an earth science term. Geological heritage represents the common scientific wealth of a country. Geosites has to be located and taken into inventory as defined in international standards. A Geosite framework list is a must for classification in order to fully evaluate their scientific potential and has been developed and published for Turkey. The most effective way to protect geosites is increasing the awareness of the society and by geoparks and geotourism applications. Turkey has great potential for this applications and awaits administrator's attention. However, it must be stated that, unplanned and careless geotourism is the most effective threat on geological heritage with many negative examples.

The increase of applications for Cultural Geology and Geological Heritage in Turkey and other countries will contribute to earth sciences and also be a major investment to efforts in creating information based society.

\section{DEĞİNILEN BELGELER}

Altunel, E., 2012. Kültürel Jeoloji; jeolojinin insanoğlunun yaşamı üzerindeki etkileri. İç; N. Kazanc1 ve A. Gürbüz (Ed), Kuvaterner Bilimi, Ankara Üniversitesi Yayını, 350, 195-2014.

Arpat, E., 1976. İnsan ayağ 1 iz fosilleri; yitirilen bir doğal anıt. Yeryuvar $\iota$ ve İnsan, 1/4, 65-66.

Arpat, E. ve Güner, Y., 1976. Ağrı buz mağarası; ender bir doğal anıt. Yeryuvarl ve İnsan, 1/1, 95-96.

Burek, C.V. ve Prosser, C.D., 2008. The History of
Geoconservation. Geological Society, Spec. Pub., London, 300, 312.

Callaway, E., 2016. Ancient genome delivers 'Spirit Cave Mummy' to US tribe; Sequencing proves Native American roots of 10,600-year-old skeleton. Nature, 540 (8 December 2016), 178179.

Doughty, P., 2008. How things began: the origin of geological conservation. In: The History of Geoconservation (Ed. Burek ve Prosser), Geol. Soc. Spec. Pub., London, 300, 7-16.

Dowling, R. ve Newsome, D., 2005. Geotourism. Elsevier Pub., Amsterdam. 205.

Erikstad, L. 2008. History of geoconservation in Europe. In: The History of Geoconservation (Ed. C.V. Burek ve C.D. Prosser), Geol. Soc. Spec. Pub., London, 300, 249-256.

Ergin, M., 2003. Orhun Abideleri. Hisar yayınları, Istanbul, 27, $192 \mathrm{~s}$.

Garcia, T., Féraud, G., Falguères, C., de Lumley, H., Perrenoud, C., Lordkipanidze, D. (2010). Earliest human remains in Eurasia: New $40 \mathrm{Ar} / 39 \mathrm{Ar}$ dating of the Dmanisi hominid-bearing levels, Georgia. Quaternary Geochronology, 5 (4), $443-$ 451.

Güleç, E., Howell, F.C. and White, T., (1999). Dursunlu - A New Lower Pleistocene Faunal and Artifact Bearing Locality in Southern Anatolia. Ulrich, H. (ed.), Hominid Evolution: Lifestyles and Survival Strategies, Archaea, 349-364.

ICOMOS (International Council on Monument and Cities), 2015. Cultural heritage of water in the Middle East and Maghrep. 1st edition. UNESCO World Heritage Convention, Charanton, France, 301.

Kappelmann, J., Alçiçek, M.C., Kazancı, N., Schultz, M., Özkul, M, Şen, Ş., 2008. BriefCommunication: First Homo Erectus from Turkey and Implications for Migrations into Temperate Eurasia. American Journal of Physcial Anthropology, 135, 110-116. 
Kazanc1, N., 2005. Kültürel Jeoloji. Mavi Gezegen, 12, 4-5.

Kazanc1, N. 2010. Jeolojik Koruma; Kavram ve Terimler. Jeolojik Mirası Koruma Derneği yayını, Ankara, 60.

Kazanc1, N. ve Gürbüz, A., 2014. Jeolojik miras nitelikli Türkiye doğal taşları. Türkiye Jeoloji Bülteni 57, 19-44.

Kazanc1, N., Şaroglu, F., Kırman, E., Uysal, F., 2005. Basic threats on geosites and geoheritages in Turkey. Proceedings of Second Conference on Geoheritage of Serbia, June 2004 Belgrade, Sebia-Montenegro,149-153.

Kazancı, N., Şaroğlu, F., Doğan, A., Mülazımoğlu, N., 2012. Geoconservation and geoheritage in Turkey. In: Geoheritage in Europe and its Conservation (Eds W.A.P. Wimbledon \& S. Smith-Meyer), ProGeo Spec.Pub, Oslo, Norway, 366-377.

Kazanc1, N., Şaroğlu, F., Suludere, Y., 2015. Türkiye Jeositleri Çatı Listesi. MTA Dergisi, 151, 261-270.

Ketin, İ., 1970. Türkiye'de önemli jeolojik aflormanların korunması. Türkiye Jeoloji Kurumu Bülteni, XI/2, 90-93.

Küçük, M. ve Ertürk, E., 2013. Biodiversity and protected areas in Turkey. Sains Malaysiana 42, $1455-1460$.

Öngür, T., 1976. Doğal anıtların korunmasında yasal dayanaklar. Yeryuvarı ve İnsan, 1/4, 17-23.

Özdemir, U., Göncüoğlu, M.C., Tütüncü, G., Tanca, N., Tümer, A., 1986. Doğal Anıtlar. Ege Univ. Fen Fakültesi Dergisi, Ser. B, 8, 221-230.
Pederson, N., Hessl, A.E., Baatarbileg, N. , Anchukaitis, K.J. , Di Cosmo, N., 2014. Pluvials, droughts, the Mongol Empire, and modern Mongolia. Proceedings of the National Academy of Sciences - PNAS 111, 4375-4379.

ProGeo Group, 1998. A first attemt at a geosites framework for Europe -an lUGS initiative to support recognition of World heritage and European geodiversity. Geologica Balcanica 28, 5-32.

TUİK, 2015. Türkiye 2015 İstatistikleri. Türkiye İstatistik Kurumu, Ankara, Türkiye.

Wimbledon, W.A.P. 1996. National site election, a stop on the road to a European Geosite List. Geologica Balcanica 26, 15-27.

Wimbledon, W.A.P., Benton, M.A., Berins, R.E. 1995. The development of a methodology for the selection of British geological sites for conservation. Part I, ProGEO. Modern geology 20, 59-202.

Wimbledon, W.A.P., Smith-Meyers, S (eds). 2012. Geoheritage in Europe and Its Conservation. PeoGEO Spec. Pub., Oslo, Norway, 405.

Yasuda Y. (Ed), 2002. The Origins of Pottery and Agriculture. Roli Books, Lustre Press, Kyoto, Japan, 399.

Zorich, Z., 2016. New dates for the oldest cave printings. Arcaheology, 221 (Haziran sayıs1), 4551. 